\title{
ANALYSIS OF RELIABILITY INDICES FOR THE POWER CONTACT CONNECTION ELEMENT
}

\author{
Evgenya Timoshenko ${ }^{1}$, Evgeny Kravchenko ${ }^{1 a}$ \\ ${ }^{1}$ National Research Tomsk Polytechnic University, 634050 Tomsk, Russia
}

\begin{abstract}
In this paper we examine the reliability of contact connections. By numerical modeling was defined the failure rate of contact connection.
\end{abstract}

\section{Introduction}

In today's world there is a lot of switching products, they are found in almost all fields of human activity. The main function of switching products is connection of elements on which flows the electricity. Due to the increasing complexity of technical systems, ensuring reliability becomes a very important fact for the proper functioning of the device. Relevance of research subject is caused needs to increase the level of reliability and safety electrical equipment. The failure rate electrical contact is increasing of an admissible limit temperature the most heated point their elements or connection [1, 2].

The purpose of work. Failure rate analysis of element contact connection by numerical modeling their temperatures fields.

The object of research is a contact connection - an element of power switching device..

\section{Construction of model of a single-wire conductor with socket terminals}

In the first part of work was constructed a three dimensional model of the contact connection by using Solidworks, which is presented on Fig.1.

\footnotetext{
a Corresponding author : kevatp@tpu.ru
} 


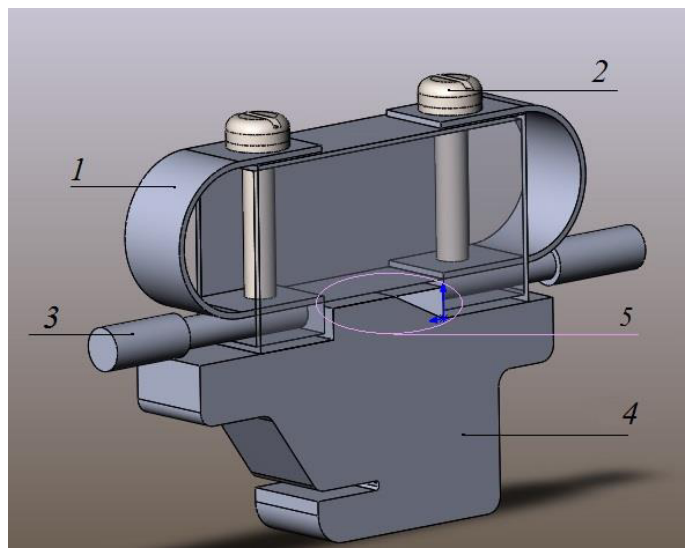

Figure 1. Contact connection with socket terminals: 1 - terminal block; 2 - screw ; 3 - conductor ; 4 - corps; 5 - section plate;

\section{Numerical modeling of temperature fields of an element contact connection}

The study of bubble rising dynamics was performed at following parameters: $D=(0.82-5.5) \mathrm{mm}$, $\mu_{l}=\left(10^{-3}-2.4\right) \mathrm{Pa} \cdot \mathrm{s}, \rho_{l}=(935-1260) \mathrm{kg} / \mathrm{m}^{3}, \mathrm{Re}=3.5 \cdot 10^{-3}-0.6$; surfactant content $z=(0.01-0.13) \%$.

In the second part of work was simulated the temperature field of the device by using the program ABC Pascal. An example of this method is the studies carried out by Kravchenko [3, 4, 5].

Results were constructed by using the program Origin Pro. During experiments was varied the value of electric current flowing through the element of contact connection.

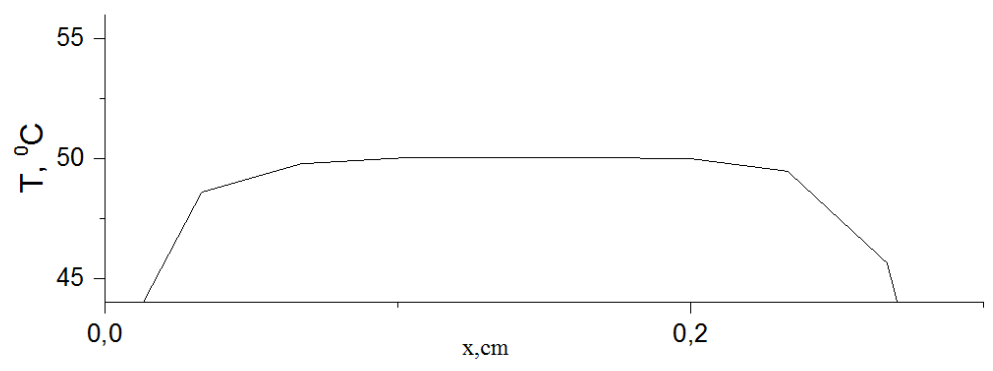

Figure 2. The temperature distribution on plate thickness in a timepoint $t=15 \mathrm{sec}$ and amperage $\mathrm{I}=4.4 \mathrm{~A}$, the environment temperature is $\mathrm{t}=25^{\circ} \mathrm{C}$

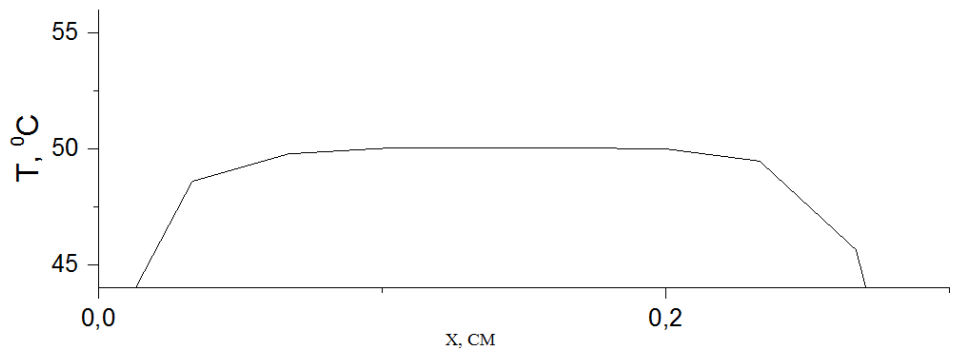


Figure 3. The temperature distribution on plate thickness in a timepoint $t=15 \mathrm{sec}$ and amperage $\mathrm{I}=10 \mathrm{~A}$, the environment temperature is $\mathrm{t}=25^{\circ} \mathrm{C}$

It is important to note that the instrumental methods of inspection of electrical equipment (for example thermography inspection) do not allow to obtain the distribution of temperature fields inside the contact connection.

On the basis of the obtained data it is possible to draw a conclusion that temperature reaches its extremum in the middle of a plate.

\section{Reliability analysis of contact connection}

For the analysis of reliability were selected two mathematical model Arrhenius and multiplicative. The multiplicative mathematical model of evaluating the reliability an element contact connection:

$$
\lambda_{e}=\lambda_{b} * K_{p} * K_{f} * K_{k} * K_{c}
$$

Where $\lambda_{b}$ is basic failure rate of the power device; $K_{p}$ the mode coefficient depending on electric load and temperature; $K_{f}$ is the coefficient of the functional specifics of the regime of the device; $K_{k}$ is the coefficient of a level of quality of the device; $K_{c}$ is the stiffness coefficient of operating conditions. Arrhenius's model for an assessment of reliability of the diode module:

$$
\lambda_{a}(T)=C^{*} \exp \left(\frac{-E}{k T}\right)
$$

where: $\mathrm{C}$ is a constant, $\mathrm{E}$ is the activation energy, $\mathrm{k}$ is the Boltzmann constant.

Numerical modeling results are shown in Fig.4, indicators of reliability (failure rate). The behavior of the failure rate $\lambda(\mathrm{t})$ reflects not only the significant differences in the estimates of the reliability of models (1) and (2), but also a high degree of dependence of predictive Arrhenius model on settlement temperature.

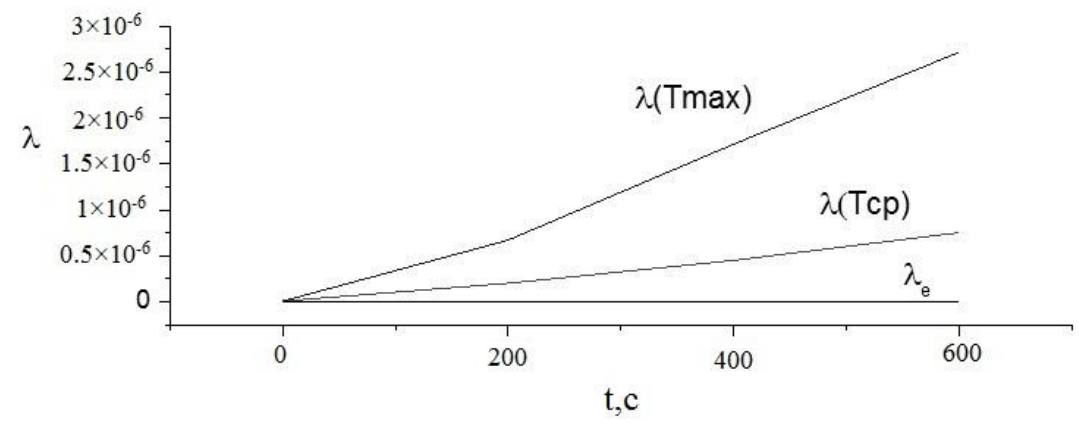

Figure 4. Failure rate of single-wire conductor at an ambient temperature $\mathrm{T}=250 \mathrm{C}, \mathrm{t}=600 \mathrm{sec}$. ( $(\lambda \mathrm{e}-$ multiplicative model $; \lambda$ (Tav) - Arrhenius model (with Tav); $\lambda$ (Tmax) - Arrhenius model (at Tmax).

\section{Conclusion}

On the basis of the work it is possible to draw a conclusion that for a definite level of reliability and safety of the electrical equipment, it is necessary to use real temperatures field.

The method of thermography inspection is not valid for most electrical equipment and this method of analysis has a number of limitations. Moreover, it is too expensive experimentally check big number contact connection. 
A summary of the main findings and of the principal issues, the more suitable way to definite reliability indices power contacts connection is numerical modeling based on real temperatures.

The work was supported by the RFFI (project № 15-38-50595).

\section{References}

1. Y. Zhao, L. Chen, Q. Yan, C. Li, MATEC Web Conf., 21, 7 (2015)

2. C. Banc, J. Guinet, E. Doche, Microelectron Reliab 52, 1797 (2012)

3. E.V. Kravchenko, G.V. Kuznetsov, MATEC Web Conf., 19, 6 (2014)

4. G. V. Kuznetsov, E. V. Kravchenko, EPJ Web Conf., 82, 6 (2015)

5. G. V. Kuznetsov, E. V. Kravchenko, Elektromagnitnye Volny and Elektronnye Systemy, 10 (1112), 19 (2005) 